\title{
UV-VISIBLE OPTICAL ABSORBANCE OF GRAPHENE OXIDE IN COPPER IONIC LIQUID SYNTHESIZED VIA ELECTROCHEMICAL METHOD ASSISTED BY A COPPER COIL
}

\author{
Wipsar Sunu Brams Dwandaru1,a), Oktiana Lusi Priyani ${ }^{1}$, Bagas Prakoso1), \\ Iman Santoso $^{2)}$, Arif Rahman ${ }^{1)}$, Rhyko Irawan Wisnuwijaya ${ }^{1)}$ \\ ${ }^{1}$ Physics Education Department, Faculty of Mathematics and Natural Science, Universitas Negeri Yogyakarta, \\ Karangmalang Complex, Yogyakarta, 55281, Indonesia. \\ ${ }^{2}$ Physics Department, Faculty of Mathematics and Natural Science, Universitas Gadjah Mada, Yogyakarta, \\ Indonesia. \\ Email: ${ }^{a)}$ wipsarian@uny.ac.id
}

\begin{abstract}
An optical absorbance study using Ultraviolet-Visible (UV-Vis) spectrophotometer device has been conducted on graphene oxide $(\mathrm{GO})$ in copper $(\mathrm{Cu})$ ionic liquid using electrochemical exfoliation combined with a direct current (DC) electrical circuit of copper coil given inside the electrolyte solution. The electrolyte solutions used are sulfuric acid (H2SO4) and chloride acid ( $\mathrm{HCl})$. The UV-Vis spectrum of the samples shows absorbance peaks at around $214 \mathrm{~nm}$ to $218 \mathrm{~nm}$ and shouldering peaks around 245 $\mathrm{nm}$ to $249 \mathrm{~nm}$. The first peak corresponds to the existence of copper $(\mathrm{Cu})$ ionic liquid in the solution, whereas the shouldering peak is related to the occurrence of GO material. A comparison between UVVis spectral of graphite in dimethylformamide (DMF) and GO in $\mathrm{Cu}$ ionic liquid in DMF resulted in the existence of a blue shift which signifies the production of $\mathrm{Cu}$ ionic liquid from the $\mathrm{Cu}$ coils inside the electrolyte solution. Increasing the concentration of the solution increases the absorbance peaks. Furthermore, raising the number of loops yields in the increase of the absorbance value at the first peaks that show $\mathrm{Cu}$ ionic liquid, but tends to decrease the absorbance value of the shouldering peaks of the GO material.
\end{abstract}

Keywords: graphene oxide, copper ionic liquid, electrochemical method, solenoid coil.

\section{INTRODUCTION}

Graphene oxide (GO) is a precursor for obtaining graphene material. The latter is a novel material with superior optical, electrical, and magnetic properties. However, GO is also a material with many applications, such as biosensors [1-3], biomedical drug delivery [4-6], optoelectronics [7,8], solar cells [9-11], composite materials [12,13], batteries [14-16], and supercapacitors [17,18]. The many applications of GO immediate challenging problem of producing large-scale GO without sacrificing its superior physical and chemical properties. The synthesis of GO may be conducted using various methods such as Hummers' method [19-21] and solvothermal [22, 23].

In this study, we use an electrochemical method $[24,25]$ in producing GO. The exfoliation is done by peeling thin layers of graphite, which is used as one of the electrodes in the electrochemical process. A modification to the method is made by applying an additional material that is a solenoid 
coil made from copper metal $(\mathrm{Cu})$. The latter is submerged into the electrolyte solution and given a constant direct current. Cooper ions will be produced in the electrolyte solution.

On the other hand, the graphite electrode will be exfoliated into the electrolyte producing graphite oxide material. By further processing of filtration, purification, and ultrasonication, GO in Cu ionic liquid is obtained. The ionic liquid is essentially salt in aqueous solution. It is used in various applications, for example as a solvent [26] and in batteries [27].

Moreover, the data obtained in this study is limited to UV-Visible (UV-Vis) spectroscopy results. This is of course far from ideal as other characterizations are needed to confirm and elaborate the results obtained in this study. However, we would like to emphasize on the optical properties of the material, especially from the absorbance of the material towards ultraviolet and visible light spectral. Hence, we would want to determine the wavelengths at the maximum (peak) absorbance and possible shifts of the peaks. These peaks indicate specific materials inside the sample being tested.

\section{MATERIALS AND METHODS}

This is an experimental study in the synthesis of GO in $\mathrm{Cu}$ ionic liquid via the electrochemical method. The electrolysis apparatus may be observed in Fig. 1. The electrolysis is carried out in a mixture of strong electrolytes of $0.5 \mathrm{M} \mathrm{H} 2 \mathrm{SO} 4$ and $30 \% \mathrm{KOH}$ as much as $200 \mathrm{ml}$ and $11 \mathrm{ml}$, respectively. Graphite (Faber Castell 2B pencil) and platinum rods are used as electrodes with the same length of $6 \mathrm{~cm}$ and set at $11 \mathrm{~cm}$ distance apart. The electrodes are connected to a $15 \mathrm{~V}$ power supply and bias power supply. Also, a Cu solenoid coil connected to a DC electrical circuit is submerged into the electrolyte and given a constant potential difference of 10 volts. The number of solenoid coils is varied, i.e., $\mathrm{N}=500,1000$, and 1500 coils.

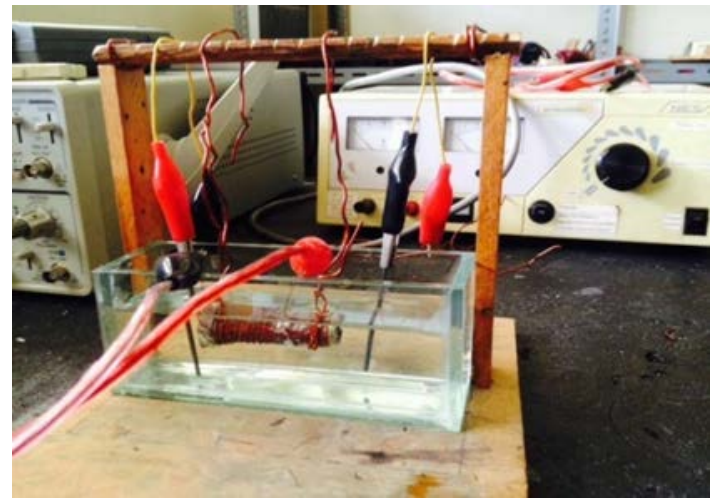

(a)

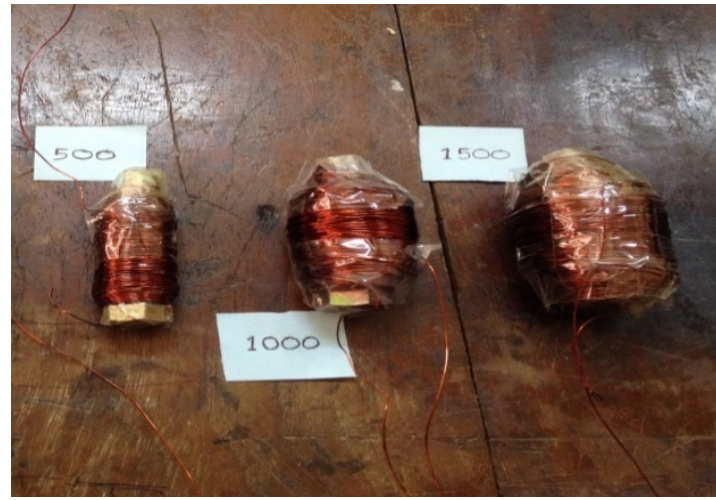

(b)

Figure 1. (a) The electrolysis apparatus used in this study and (b) the Cu solenoid coils with a different number of coils, viz.: $\mathrm{N}=500,1000$, and 1500 coils (from left to right).

The experimental procedure in obtaining graphite oxide may be given as follows. Firstly, the electrodes are given a potential difference of 3 volts for 3 minutes. Then, alternating voltages of +15 volts and -15 volts are given for 3 minutes each for a total of 30 minutes. This process leads to erosion of the graphite rod into thinner layers of graphite oxide in the electrolyte [Fig. 2(a)]. Next, filtration and purification procedure of the electrolyte containing graphite oxide resulted from the electrolysis process is conducted using vacuum filtration technique [Fig. 2(b)]. The powder obtained is rinsed using distilled water several times until the $\mathrm{pH}$ of powder is neutral. The powder is then annealed at 100 0C for 4 hours and then weighted for 0.3, 0.6, and $0.9 \mathrm{mg}$. Each of the weighted powder is then mixed with dimethylformamide (DMF) solvent, solving with a concentration variation of $0.1,0.2$, and $0.3 \mathrm{mg} / \mathrm{mL}$, respectively. All the solutions obtained are then sonicated for 30 minutes using an ultrasonic bath. A comparison of the solutions before and after the sonication may be observed in Fig. 3, i.e., the solution after sonication becomes more feculent. Finally, the solutions are centrifuged at $500 \mathrm{rpm}$ for 15 minutes and characterized using UV-Vis spectrophotometer. The procedure above is repeated for 500, 1000, and 1500 number of coils. 


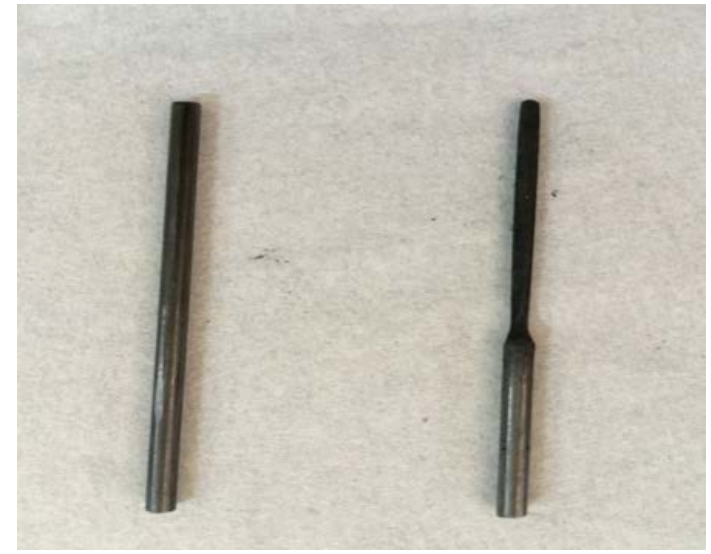

(a)

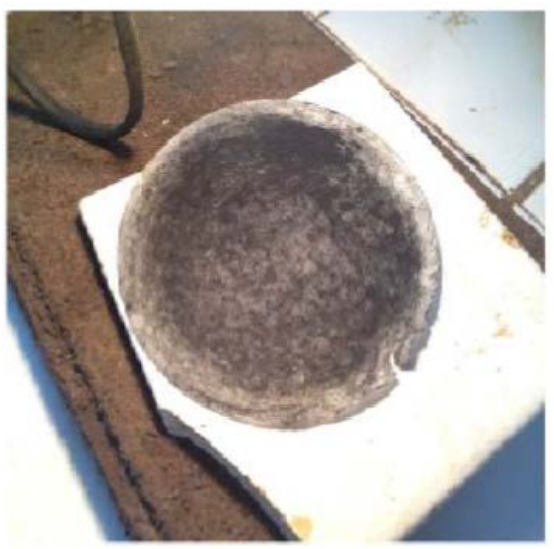

(b)

Figure 2. (a) graphite pencil before (left) and after (right) the electrolysis process, (b) the powder obtained after filtering and purification process.
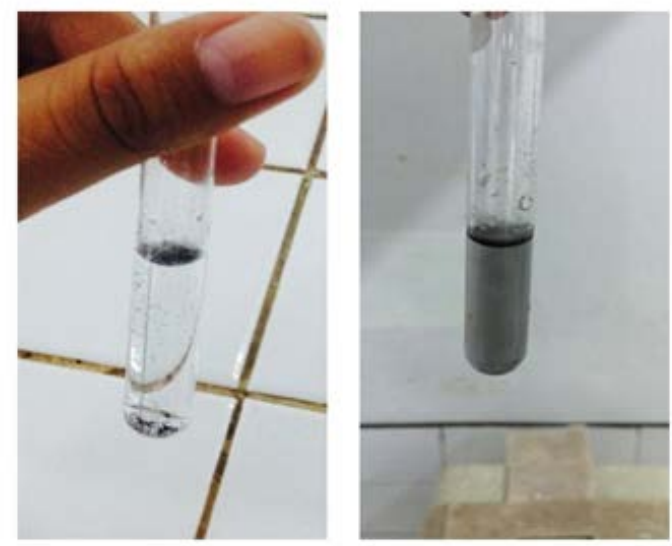

Figure 3. The solution in DMF solvent before sonication (left), and the solution after sonication (right).

\section{RESULTS ANDDISCUSSION}

The results of this study are UV-Vis spectroscopy data obtained for the samples with a solution concentration and some coil variations. A comparison of UV-Vis spectroscopy data between graphite material and the solution obtained from the experiment (with $\mathrm{N}=1000$ and $0.3 \mathrm{mg} / \mathrm{ml}$ of powder concentration after electrolysis) may be perceived in Fig. 4. The (red) dashed line is graphite in DMF, whereas the (purple) solid line is the solution obtained from the treatment. It may be observed that a blue shift appears to occur from a broad peak of the graphite in DMF to a more characteristic peak at $216.5 \mathrm{~nm}$ and a shouldering peak at $249 \mathrm{~nm}$. A peek at $216.5 \mathrm{~nm}$ suggests an existence of $\mathrm{Cu}$ ionic liquid accompanied by GO material. The Cu solenoid coil tends to shift the UV-Vis to a shorter wavelength by producing $\mathrm{Cu}$ ions into the electrolyte as the coil is eroded, whereas the GO tends to change the peak to a longer wavelength. This is in line with Liu et al. (2014) where it is reported that the peak of GO is obtained around $230 \mathrm{~nm}$ before the electrochemical process and red shifted toward $260 \mathrm{~nm}$ after the electrochemical process [28]. 


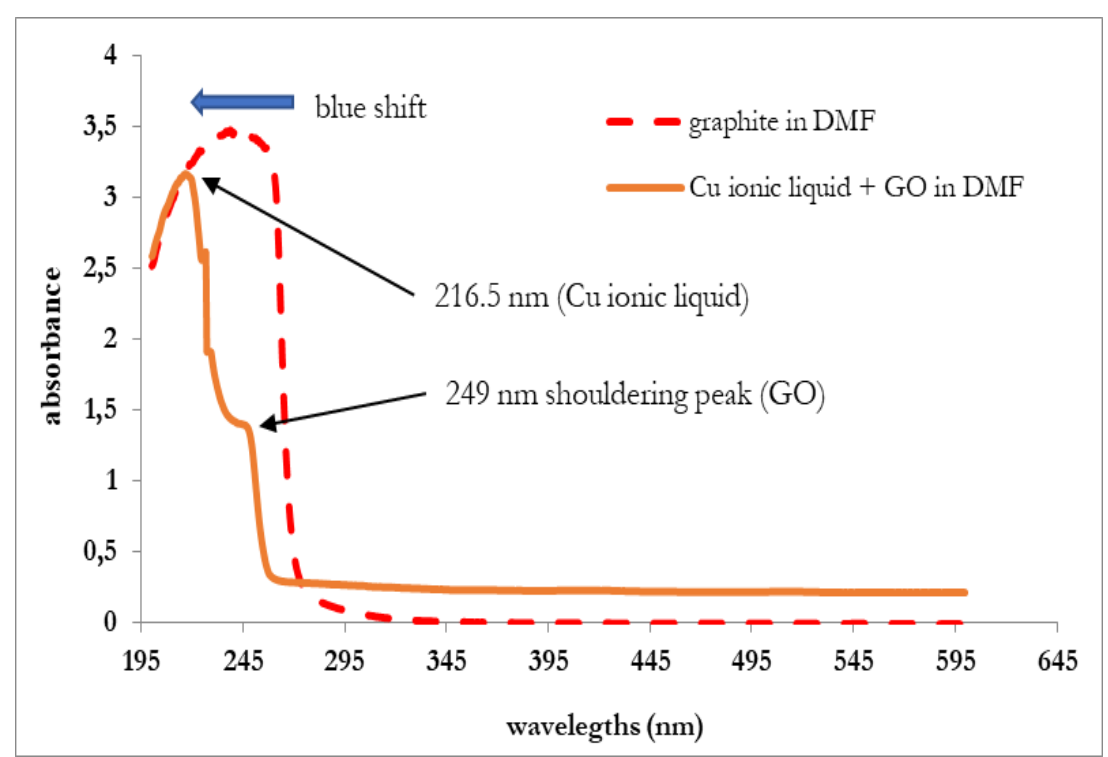

Figure 4. Comparison of UV-Vis spectroscopy data between graphite and GO in Cu ionic liquid solutions in DMF solvent.

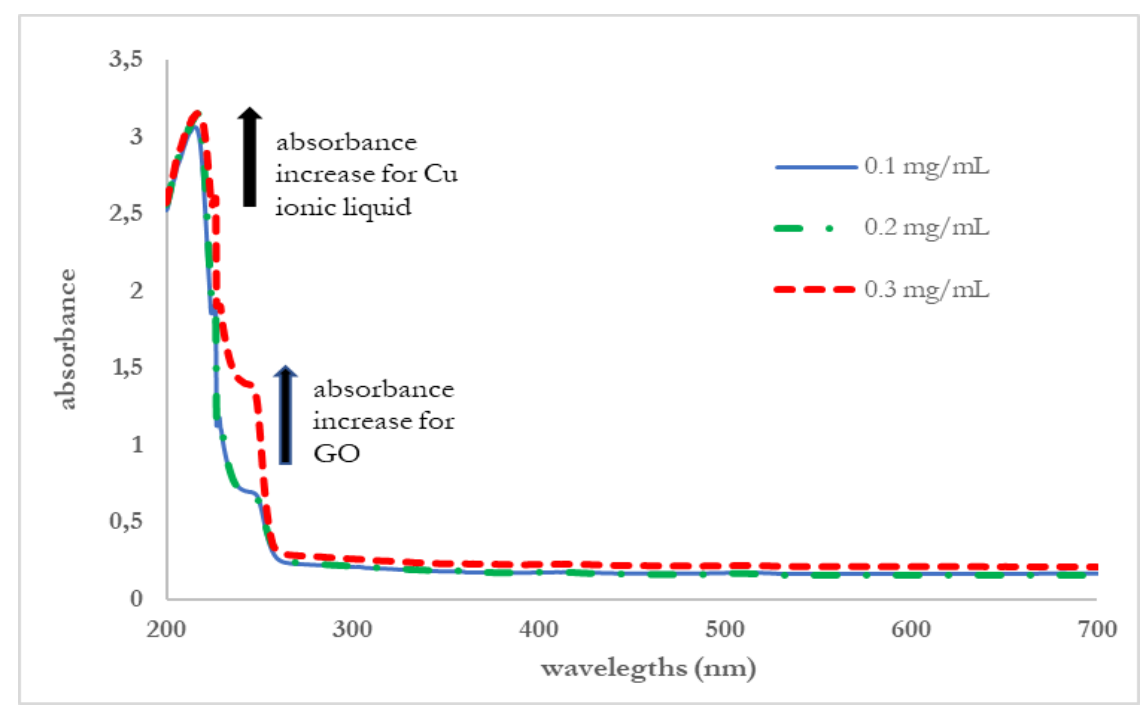

Figure 5. Comparison of UV-Vis spectroscopy data with concentration variation of the $\mathrm{Cu}$ in ionic liquid solutions.

Next, we obtain UV-Vis spectroscopy data of GO in Cu ionic liquid solutions in DMF with concentration variation. This may be observed in Fig. 5. The (red) dashed, (green) dash-dotted, and (blue) solid lines are the UV-Vis spectroscopy data for GO in $\mathrm{Cu}$ ionic liquid concentration of 0.1 $\mathrm{mg} / \mathrm{mL}, 0.2 \mathrm{mg} / \mathrm{mL}$, and $0.3 \mathrm{mg} / \mathrm{mL}$. The data are consistent with Lambert-Beer law, where increasing the concentration of the solution, causes the absorbance to increase as well. The peaks obtained from the variation of the concentration are the same, that is, at $216 \mathrm{~nm}$ and $245 \mathrm{~nm}$.

Finally, UV-Vis data results with some coil variation may be observed in Fig. 6. The (blue) solid, (red) dash-dotted, and (green) dashed lines are the UV-Vis data for 500 coils, 1000 coils, and 1500 coils of $\mathrm{GO}$ in $\mathrm{Cu}$ ionic liquid solutions, respectively. An interesting finding is that as the number of coils is increased, the absorbance for the $\mathrm{Cu}$ ionic liquid increases, whereas the absorbance of the GO tends to decrease. This makes sense as the number of coils gets larger, the number of $\mathrm{Cu}$ ions released by the coils inside the electrolyte increase as well. However, the increase in the number of $\mathrm{Cu}$ ions disrupts the shedding of the graphite rod inside the electrolyte hence decreasing the GO production. 


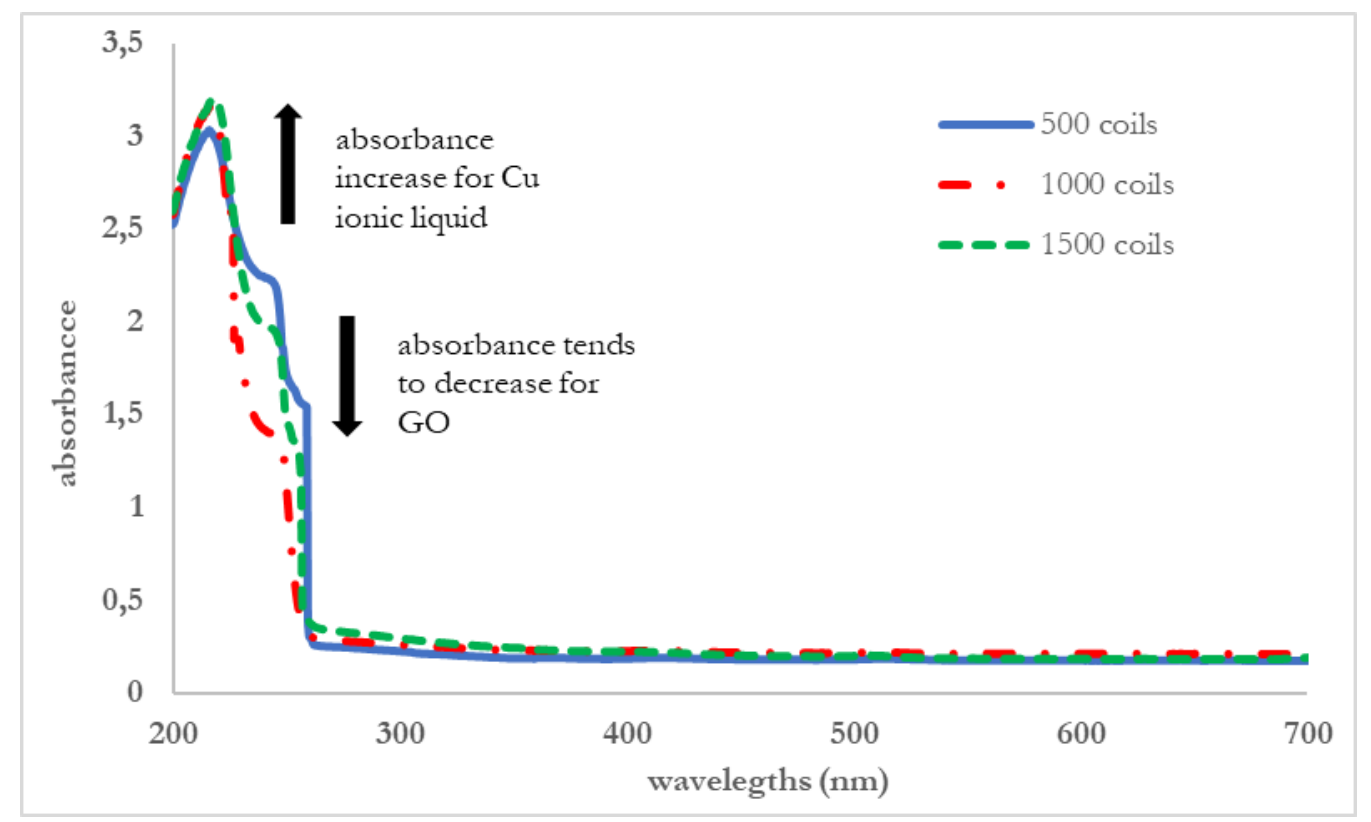

Figure 6. Comparison of UV-Vis spectroscopy data with some coil variations.

\section{CONCLUSION}

GO in $\mathrm{Cu}$ ionic liquid has been synthesized using the electrochemical method. The UV-Vis spectroscopy data show that a blue shift occurs from graphite to GO in $\mathrm{Cu}$ ionic liquid in DMF solution. Moreover, increasing the concentration of graphite oxide in DMF increases the amount of $\mathrm{GO}$ in $\mathrm{Cu}$ ionic liquid. Finally, increasing the number of solenoid coil increases the amount of $\mathrm{Cu}$ ionic liquid but decreases the GO material.

\section{ACKNOWLEDGEMENTS}

This study is supported by the Faculty of Mathematics and Natural Science, Universitas Negeri Yogyakarta. The authors would also like to thank the Physics Department, Universitas Gadjah Mada for conducting the experiments.

\section{REFERENCES}

[1] Z. Wang et al., "A nanoscale graphene oxide-peptide biosensor for real-time specific biomarker detection on the cell surface,” Chem. Commun., vol. 48, pp. 9768-9770, 2012. DOI 10.1039/C2CC31974H.

[2] H. Zhang et al., "Fluorescent biosensors enabled by graphene and graphene oxide," Biosensors and Bioelectronics, vol. 89, pp. 96-106, 2017. DOI 10.1016/j.bios.2016.07.030.

[3] B. Cai et al., "Ultrasensitive Label-Free Detection of PNA-DNA Hybridization by Reduced Graphene Oxide Field-Effect Transistor Biosensor,” ACS Nano, vol. 8, pp. 2632-2638, 2014. DOI 10.1021/nn4063424.

[4] C. Yao et al., "Graphene oxide and creatine phosphate disodium dual template-directed synthesis of GO/hydroxyapatite and its application in drug delivery,” Materials Science and Engineering: C, vol. 73, pp. 709-715, 2017. DOI 10.1016/j.msec.2016.11.083.

[5] X. Ma et al., "A functionalized graphene oxide-iron oxide nanocomposite for magnetically targeted drug delivery, photothermal therapy, and magnetic resonance imaging," Nano Res., vol. 5, pp. 199-212, 2012. DOI 10.1007/s12274-012-0200-y. 
[6] L. Zhang et al., "Functional graphene oxide as a nanocarrier for controlled loading and targeted delivery of mixed anticancer drugs,” Small, vol. 6, pp. 537-544, 2010. DOI 10.1002/smll.200901680.

[7] G. Eda and M. Chhowalla, "Chemically Derived Graphene Oxide: Towards Large-Area Thin-Film Electronics and Optoelectronics," Adv. Mater., vol. 22, pp. 2392-2415, 2010. DOI 10.1002/adma.200903689.

[8] X. Wan et al., "Focusing on Energy and Optoelectronic Applications: A Journey for Graphene and Graphene Oxide at Large Scale,” Acc. Chem. Res., vol. 45, pp. 598-607, 2012. DOI 10.1021/ar200229q.

[9] X. Wang et al., "Transparent, Conductive Graphene Electrodes for Dye-Sensitized Solar Cells,” Nano Lett., vol. 8, pp. 323-327, 2008. DOI 10.1021/nl072838r.

[10] S.-S. Li et al., "Solution-Processable Graphene Oxide as an Efficient Hole Transport Layer in Polymer Solar Cells,” ACS Nano, vol. 4, pp. 3169-3174, 2010. DOI 10.1021/nn100551j.

[11] E. Nouri et al., "Inverted perovskite solar cells based on lithium-functionalized graphene oxide as an electron-transporting layer," Chem. Comm., vol. 53, pp. 1630-1633, 2017. DOI 10.1039/C6CC09876B.

[12] Y. Liu et al., "Carboxyl-functionalized graphene oxide-polyaniline composite as a promising supercapacitor material,” J. Mater. Chem., vol. 22, pp. 13619-13624, 2012. DOI 10.1039/C2JM32479B.

[13] Y. Xu et al., "Strong and ductile poly(vinyl alcohol)/graphene oxide composite films with a layered structure,” Carbon, vol. 47, pp. 3538-3543, 2009. DOI 10.1016/j.carbon.2009.08.022.

[14] Z.-L. Wang et al., "Graphene Oxide Gel-Derived, Free-Standing, Hierarchically Porous Carbon for High-Capacity and High-Rate Rechargeable Li-O2 Batteries," Adv. Funct. Mater., vol. 22, pp. 3699-3705, 2012. DOI 10.1002/adfm.201200403.

[15] P. Han, et al., "Graphene oxide nanoplatelets as excellent electrochemical active materials for $\mathrm{VO} 2+/ \llbracket \mathrm{VO} \rrbracket 2^{\wedge+}$ and $\mathrm{V} 2+/ \mathrm{V} 3+$ redox couples for a vanadium redox flow battery," Carbon, vol. 49, pp. 693-700, 2010. DOI 10.1016/j.carbon.2010.10.022.

[16] Z.-L. Wang et al., "Facile, mild and fast thermal-decomposition reduction of graphene oxide in air and its application in high-performance lithium batteries," Chem. Commun., vol. 48, pp. 976-978, 2012. DOI 10.1039/C2CC16239C.

[17] L. L. Zhang et al., "Layered Graphene Oxide Nanostructures with Sandwiched Conducting Polymers as Supercapacitor Electrodes,” Langmuir, vol. 26, pp. 17624-17628, 2010. DOI 10.1021/la103413s.

[18] B. Yuan et al., "Graphene oxide/nickel oxide modified glassy carbon electrode for supercapacitor and nonenzymatic glucose sensor,” Electrochimica Acta, vol. 88, pp. 708-712, 2013. DOI 10.1016/j.electacta.2012.10.102.

[19] J. Chen, et al., "An improved Hummers method for eco-friendly synthesis of graphene oxide,” Carbon, vol. 64, pp. 225-229, 2013. DOI 10.1016/j.carbon.2013.07.055.

[20] C. J. Guerrero and B. F. Caballero, "Graphene oxide powders with different oxidation degree, prepared by synthesis variations of the Hummers method,” Materials Chemistry and Physics, vol. 153, pp. 209-220, 2015. DOI 10.1016/j.matchemphys.2015.01.005.

[21] K. Gerani et al., "Enhancement in Performance of Sulfonated PES Cation-Exchange Membrane by Introducing Pristine and Sulfonated Graphene Oxide Nanosheets Synthesized through Hummers and Staudenmaier Methods," Polymer-Plastics Technology and Engineering, vol. 56 no. 5, pp. 543-555, 2017. DOI 10.1080/03602559.2016.1233260. 
[22] G. Wang et al., "Synthesis of enhanced hydrophilic and hydrophobic graphene oxide nanosheets by a solvothermal method," Carbon, vol. 47 no. 1, pp. 68-72, 2009. DOI 10.1016/j.carbon.2008.09.002.

[23] R. Atchudan et al., "Facile synthesis of zinc oxide nanoparticles decorated graphene oxide composite via simple solvothermal route and their photocatalytic activity on methylene blue degradation,” Journal of Photochemistry and Photobiology B: Biology, vol. 162, pp. 500510, 2016. DOI 10.1016/j.jphotobiol.2016.07.019.

[24] J. Liu et al., "A green approach to the synthesis of high-quality graphene oxide flakes via electrochemical exfoliation of pencil core,” RSC Adv., vol. 3, pp. 11745-11750, 2013. DOI 10.1039/C3RA41366G.

[25] L. Lu et al., "Graphene oxide and H2 production from bioelectrochemical graphite oxidation,” Scientific Reports, vol. 5, pp. 1-11, 2015. DOI 10.1038/srep16242.

[26] R.D. Rogers and K.R., Seddon "Ionic Liquids--Solvents of the Future?," Science, vol. 302 no. 5646, pp. 792-793, 2003. DOI 10.1126/science.1090313.

[27] M. Ishikawa et al., "Pure ionic liquid electrolytes compatible with a graphitized carbon negative electrode in rechargeable lithium-ion batteries," Journal of Power Sources, vol. 162 no. 1, pp. 658-662, 2006. DOI 10.1016/j.jpowsour.2006.02.077.

[28] Y. Liu et al., "A simple and efficient electrochemical reductive method for graphene oxide," Bull. Mater. Sci, vol. 37, pp 1529-1533, 2014. 
